Farum

Sociológico

Forum Sociológico

Série II

$26 \mid 2015$

Número 26

\title{
Futebol, Mercantilismo e Identidade no século XXI : Hegemonia e Contra-Hegemonia
}

Pedro Almeida

\section{(2) OpenEdition \\ Journals}

Edição electrónica

URL: https://journals.openedition.org/sociologico/1176

DOI: 10.4000/sociologico. 1176

ISSN: 2182-7427

Editora

CICS.NOVA - Centro Interdisciplinar de Ciências Sociais da Universidade Nova de Lisboa

Edição impressa

Data de publição: 12 dezembro 2015

Paginação: 7-16

ISSN: 0872-8380

\section{Refêrencia eletrónica}

Pedro Almeida, «Futebol, Mercantilismo e Identidade no século XXI : Hegemonia e Contra-

Hegemonia», Forum Sociológico [Online], 26 | 2015, posto online no dia 04 abril 2016, consultado o 31

março 2022. URL: http://journals.openedition.org/sociologico/1176 ; DOI: https://doi.org/10.4000/

sociologico.1176 


\title{
FUTEBOL, MERCANTILISMO E IDENTIDADE NO SÉCULO XXI: HEGEMONIA E CONTRA-HEGEMONIA
}

\author{
Pedro Almeida \\ Universidade de Coimbra, Centro de Estudos Sociais (CES-UC)
}

\begin{abstract}
Resumo
Este artigo explora o impacto que as políticas de cariz mercantil têm tido no futebol, procurando evidenciar a forma como os clubes têm assimilado as profundas transformações económicas, políticas, sociais e culturais das últimas décadas. Depois de se analisar criticamente o atual estado do debate teórico sobre futebol e sociedade, discute-se em que medida a política de governação do Athletic de Bilbao pode ser concebida como uma forma de resistência contra-hegemónica face aos crescentes processos de mercantilização que se têm vindo a impor no contexto do futebol. Desta forma, através do desafio às doutrinas dominantes, mostra-se que a pura mercantilização no futebol não deve ser entendida como uma inevitabilidade histórica.
\end{abstract}

Palavras-chave: futebol; mercantilização; governação; identidade

\begin{abstract}
This paper explores the impact commercial policies have had on football, and endeavours to show evidence of how clubs have assimilated the profound economic, political, social and cultural transformations of the last decades. Firstly, the current theoretical debate about football and society is critically analysed. There follows a discussion of how the governance of Athletic Bilbao can be perceived as a way of counter-hegemonic resistance vis-à-vis the increasingly imposed commercialisation and commodification of football. Thus, by challenging the dominant doctrine, my purpose is to show that pure mercantilism in football must not be understood as an historical inevitability.
\end{abstract}

Keywords: football; commodification; governance; identity

\section{Introdução}

A discussão teórica em torno do fenómeno do futebol iniciou-se na década de 1970 com a publicação dos primeiros trabalhos académicos, abrindo caminho a uma nova área de investigação. Não obstante a variedade de perspetivas teóricas, as pesquisas centraram-se, essencialmente, na questão da violência no contexto britânico (Marsh, 1978; Dunning, 1993; Armstrong, 1998). Ainda que os estudos se tenham alargado a outras áreas geográficas e culturais, nomeadamente à Europa do Sul (Lago e Biasi, 1994; Astrinakis, 2002; Marivoet, 2009) e América Latina (Alabarces, 2002; Pimenta, 2000), as grandes linhas de investigação continuam a incidir em questões de violência e identidade. Assim, o enfoque excessivo nesta área de investigação relegou para segundo plano as abordagens que procuram relacionar as políticas económicas de mercado livre e o modo como os clubes e adeptos lidaram com estas profundas transformações.

As mudanças sociais, culturais, políticas e económicas que marcaram as sociedades contemporâneas das últimas décadas têm tido um impacto significativo no futebol. Um pouco por todo o mundo, os grandes clubes têm vindo a sofrer profundas mutações. A crescente internacionalização e comercialização da modalidade transformou os clubes com maior projeção em corporações transnacionais, processo para o qual contribuíram, entre outros agentes, as grandes companhias multinacionais. O papel das grandes corporações na busca da maximização do lucro, os interesses financeiros dos media, das televisões e dos organismos que tutelam as competições nacionais e internacionais, acentuou-se na última 
década como reflexo do fortalecimento das políticas neoliberais nas sociedades contemporâneas.

Os adeptos, por seu turno, viram-se progressivamente relegados para o fundo de uma estrutura de poder, embora, ironicamente, sejam eles os responsáveis pela centralidade que o futebol ocupa na representação das culturas populares. Sendo o futebol um palco privilegiado de afirmação de identidades locais, regionais e nacionais, facilmente se depreende que uma parte significativa dos adeptos se posiciona veementemente contra o emburguesamento e a comercialização da modalidade.

Curiosamente, apesar de o paradigma mercantil ter transformado a organização e a estruturação da maioria dos clubes, existem casos pontuais em que tal não aconteceu. Neste sentido, este trabalho pretende, precisamente, estabelecer uma ponte entre os processos de regulação nacional e internacional e a filosofia de governação que tem orientado o Athletic de Bilbao. Tendo em consideração que o clube tem sido apontado como um caso contra-hegemónico, procura-se, neste artigo, perceber de que forma é que o Athletic tem lidado com as profundas alterações verificadas no futebol das últimas décadas. A escolha da equipa justifica-se pelo facto de o Athletic ter conseguido, desde a década de 1920 até aos dias de hoje, manter uma política de governação muito particular que, simultaneamente, desafia a tendência neoliberal e, ao mesmo tempo, contribui também para o reforço da identidade basca.

\section{Comercialização e mercantilização no futebol}

Os antecedentes

As políticas neoliberais que surgiram como resposta à crise mundial de 1973 e que incentivam o Estado a não participar na economia têm tido um eco cada vez maior no futebol. O neoliberalismo, ao tornar-se uma doutrina global hegemónica, desenvolveu um modo de governação que retira responsabilidade social ao Estado para a colocar em outros atores sociais, tais como as corporações transnacionais e outras organizações não governamentais. Porém, a chamada "economia de mercado" não pode ser dissociada do processo de consolidação dos estados-nação, no sentido em que foram estes dois elementos que estiveram na génese da "sociedade de mercado" (Polanyi, 2007). Nesta perspetiva, o neoliberalismo não constitui exatamente uma nova viragem na história do capitalismo, mas antes a sua intensificação e ressurgimento depois de décadas de oposição às teses keynesianas (Harvey, 2005).

Encarando o desporto em geral e o futebol em particular como um espelho da sociedade, não é, pois, de estranhar que as abordagens económi- cas hegemónicas tenham tido um forte impacto na orientação, governação e regulamentação das competições nacionais e internacionais. A crescente comercialização do futebol, fazendo parte dos projetos capitalistas mais amplos, não pode ser encarada como um fenómeno isolado, constituindo, antes, uma extensão dos processos de mercantilização na arena do desporto (Dubal, 2010).

O caso britânico ajuda a clarificar, inequivocamente, o modo como as estratégias de mercado livre tiveram um fortíssimo impacto no futebol. Tal como salienta Anthony King em The End of the Terraces, após a queda do consenso em torno das abordagens keynesianas e consequente consolidação do liberalismo económico, iniciou-se um processo de transformação dos clubes em empresas do tipo pós-fordista. Desta forma, o futebol passou a ser uma indústria de serviços que vende valores simbólicos (King, 1998: 28). De acordo com a tese de King, a análise do thatcherismo constitui uma ferramenta fundamental para a compreensão da transformação do futebol, no sentido em que a hegemonia da nova ideologia política e económica na Grã-Bretanha desempenhou um papel central na forma como se passou a pensar a própria modalidade.

Apesar de a transformação do futebol britânico (e europeu) se ter iniciado anteriormente, foi durante a década de 1980 que se assistiu à emergência e consolidação das abordagens defensoras do aprofundamento do liberalismo económico. Assim, se até então se aceitava que as instituições que governavam o futebol deviam, em nome de uma certa ética corporativista, defender e proteger os clubes de menor dimensão, com a consolidação dos argumentos do mercado livre, o panorama alterou-se substancialmente: "os clubes deveriam confrontar todo o poder do mercado e aqueles que não conseguissem auto-sustentar-se, através dos seus próprios méritos, deveriam ter a permissão de desistir do negócio" (King, 1998: 89).

Deste modo, estabelece-se um inequívoco paralelismo entre as abordagens que defendiam um aprofundamento do liberalismo económico e o futebol. Isto é, se o papel do Estado deveria ser mínimo, o suficiente para criar as condições para o mercado atuar, também a reforma do futebol deveria obedecer a estratégias de mercado livre. Tal como foi sublinhado por King (1998: 93), da mesma forma que o thatcherismo levou à exclusão social das comunidades mais empobrecidas, a consolidação dos processos de mercantilização do futebol desencadeou, na prática, a expulsão dos estádios de uma significativa parte da classe trabalhadora.

A tentativa de chamar um novo tipo de público, proveniente da classe média e média-alta, desencadeou-se a diferentes níveis. Por exemplo, o combate ao hooliganismo ${ }^{1}$ fez parte de um vasto conjunto de medidas $^{2}$ que procurou transformar o futebol num 
negócio altamente lucrativo de acumulação de capital (Dubal: 2010: 127). Assim, os processos de comercialização e mercantilização foram conquistando um espaço cada vez maior nas estruturas envolventes na organização e governação do futebol, quer a nível europeu, quer a nível mundial.

\section{A Lei Bosman}

Uma das grandes mudanças ocorridas na governação internacional do futebol deveu-se à introdução da chamada "Lei Bosman", que permitiu aos jogadores, após a finalização dos contratos que os ligavam aos respetivos clubes, a transferência para outro clube europeu, ficando a sua nova entidade patronal isenta do pagamento de qualquer compensação financeira ao antigo clube. A "Lei Bosman" entrou em vigor na Europa em 1995, na sequência de uma disputa legal que se prolongou desde 1988, entre o jogador belga Jean-Marc Bosman e a sua entidade empregadora, o RFC Liège.

$\mathrm{O}$ atleta, apoiando-se nas leis que regiam o mercado de trabalho europeu, nomeadamente no Tratado de Roma, argumentava que as restrições impostas pelos clubes a propósito do processo de transferência iam contra a livre circulação de trabalhadores. Após o conflito jurídico que opôs o jogador ao clube e às entidades reguladoras das competições nacionais e internacionais, o Supremo Tribunal da Bélgica e o Tribunal Europeu de Justiça deram razão ao atleta, abrindo caminho ao aprofundamento do capitalismo no futebol e, consequentemente, ao enfraquecimento do papel das entidades reguladoras (Banks, 2002).

As implicações da Lei Bosman fizeram-se sentir além das fronteiras da Europa, possibilitando a criação de um mercado global no futebol. O desnivelamento económico entre as equipas acentuou-se drasticamente, já que muitas das receitas dos clubes com menor poder económico provinham, até então, precisamente, das indemnizações pagas pela aquisição do "passe" dos jogadores, mesmo que findado o contrato. Este terá sido o ponto de partida para a criação de um fosso cada vez maior entre ricos e pobres, levando inclusivamente muitos clubes à falência ou a um substancial enfraquecimento financeiro e desportivo.

Para além desse aspeto, a mobilidade internacional que os jogadores passaram a desfrutar também trouxe outras profundas mudanças, tais como o aumento exponencial dos salários dos atletas, a emergência dos "agentes desportivos" e a perda de prestígio desportivo e financeiro dos campeonatos nacionais em favor das competições europeias de clubes (Giulianotti e Robertson, 2009). Tal como se procurará evidenciar, as competições europeias passaram a ser determinantes em gerar receitas cada vez mais volumosas, quer aos clubes, quer às entidades que regulam o futebol internacional.

\section{O papel das entidades reguladoras: FIFA e UEFA}

Existe uma cultura generalizada no meio do futebol que defende a ideia de que, no passado, este teria estado sob o controlo conjunto dos adeptos e dos clubes $^{3}$. Contrariando esta visão, Sugden e outros (1998) sustentam a tese de que o futebol nunca esteve nas "mãos do povo" e afirmam que a FIFA, desde a sua formação, tem sido a base de um poder hegemónico ao serviço de uma pequena elite. Composta por 208 associações nacionais e fundada em 1904, a Fédération Internationale de Football Association é o organismo que tutela as competições internacionais, nomeadamente os campeonatos mundiais de seleções nacionais. Sendo atualmente a organização não governamental mais poderosa no contexto do futebol, a FIFA, privilegiando políticas puramente mercantis, tem vindo a aumentar exponencialmente os seus lucros 4 .

Apesar de a FIFA ter conseguido trazer grandes quantias de dinheiro para o futebol, a sua distribuição tem sido alvo de variadas críticas. De entre elas, destacam-se a má gestão financeira, a corrupção e as relações promíscuas entre membros do comité e patrocinadores oficiais (Bazel, 2011; Giulianotti e Robertson, 2009). O exemplo da Coca-Cola é ilustrativo. Nos últimos trinta anos a FIFA e a Coca-Cola têm estabelecido diversos negócios. A referida marca foi responsável pelo patrocínio de um programa da FIFA que visava formar treinadores nos países do hemisfério sul. Em troca, a FIFA apoiou a "entrada" da Coca-Cola em vários "mercados", tais como África, Europa de Leste, Médio Oriente e China (Samuels, 2008: 128). Desta forma, a FIFA, ao convidar um vasto conjunto de pessoas com experiência em negócios, merchandizing e marketing para fazer parte dos cargos executivos e dos diversos comités, conseguiu implementar o seu poder na governação do futebol, gerando, ao mesmo tempo, elevadíssimas quantias de dinheiro, provenientes essencialmente dos patrocinadores e dos direitos televisivos (Bazel, 2011).

Outro organismo que muito se tem destacado na governação internacional do futebol tem sido a UEFA, que também se tem guiado pela procura da maximização do lucro. Fundada em 1954, a Union of European Football Associations é a entidade que governa as competições europeias de futebol. Além de representar as associações nacionais europeias de futebol, a UEFA regula e controla os prémios financeiros atribuídos aos clubes, bem como os direitos televisivos. A Champions League, criada em 1992, e que reúne os melhores clubes europeus, tem sido alvo de várias críticas pelo facto de simbolizar o expoente máximo da comercialização do futebol. A principal diz respeito ao próprio formato da prova, que parece concebido para favorecer os grandes clubes europeus ${ }^{5}$ da Europa Ocidental, mais precisa- 
mente os representantes das ligas mais poderosas, tais como Inglaterra, Alemanha, Espanha, Itália e França (Giulianotti e Robertson, 2009).

Ainda que a busca pela maximização do lucro tenha acentuado, dramaticamente, as clivagens económicas entre os clubes, é importante destacar o seguinte. Assim, se por um lado, as políticas de mercado livre reforçaram a posição dos clubes de "elite" relativamente aos restantes, importa ressalvar que essas desigualdades ocorreram a vários níveis. Ou seja, se é inequívoco que clubes como o Real Madrid ou Chelsea F. C. se distanciaram, por exemplo, dos clubes "médios" europeus, também não se pode deixar de frisar que a Champions League acentuou exponencialmente o fosso económico entre o S. L. Benfica ou o F. C. Porto e os restantes clubes portugueses.

Deste modo, todo este processo funciona como uma "bola de neve", já que o sucesso desportivo dos clubes mais poderosos é altamente recompensado em termos financeiros, quer através dos prémios oferecidos pela UEFA, quer pelas transmissões televisivas $^{6}$. Por sua vez, esta entidade encontra-se numa posição excessivamente favorável, já que, devido à crescente comercialização e internacionalização da competição que governa, os lucros advindos dos direitos televisivos e dos patrocinadores são cada vez maiores. Assim, para vários autores, a intensificação das políticas capitalistas no futebol resultou na perda de algumas das suas características centrais. É, aliás, neste sentido que se podem entender as palavras de Samuels:

A menos que se faça algo para mudar a direção na qual a indústria se move, o futebol tornar-se-á apenas uma outra forma de entretenimento televisivo. Terá os seus escândalos de corrupção, as suas drogas, as suas decisões controversas, mas com poucas consequências para além do seu valor de entretenimento. Terá os seus momentos de excitação, mas não será o beautiful game. (2008: 15)

Os clubes transnacionais

As profundas mudanças ocorridas no futebol devem ser entendidas no quadro global de transformação das sociedades. À semelhança dos princípios pelos quais se regem as corporações transnacionais, também os objetivos dos clubes passaram a ser essencialmente financeiros. Clubes como o Manchester United ou o Real Madrid têm conseguido, através de estratégias de marketing, expandir a sua base de adeptos além das fronteiras dos respetivos países, conseguindo agregar muitos seguidores em diferentes regiões e continentes. Para o sucesso deste processo de "desterritorialização" cultural é importante salientar o papel dos media, nomeadamente dos canais de televisão por cabo e satélite.

A transfiguração dos grandes clubes europeus em corporações transnacionais foi um processo que se começou a fazer sentir no fim da década de 1980 e que se intensificou até aos dias de hoje (Szymanski, 2010; Taylor, 2007). A compra e controlo de alguns dos maiores clubes europeus por magnatas sem qualquer ligação aos clubes simboliza, de certa forma, a última etapa deste processo de transnacionalização. Casos como o do Chelsea ou Manchester United tornaram-se os mais mediáticos, embora haja outros exemplos semelhantes ${ }^{7}$.

Não obstante o impacto da filosofia mercantil e das políticas de mercado livre, Giulianotti e Robertson (2009: 95) defendem a ideia de que "ainda estamos longe de assistir ao triunfo inquestionável do neoliberalismo dentro do futebol". Segundo os investigadores, as políticas protecionistas que alguns países adotaram têm funcionado como travão aos processos de mercantilização e de (des)regulação. No entanto, é inquestionável que o predomínio do papel do mercado abriu caminho ao avanço das políticas de liberalização económica. Para que tal tivesse acontecido, o papel desempenhado pelas grandes corporações internacionais e pelos novos meios tecnológicos foi determinante, contribuindo, assim, para o desenvolvimento dos clubes transnacionais. Nas palavras de John Samuels, "aquilo que uma vez foi um jogo baseado nas comunidades locais, em apoio e orgulho local, transformou-se num produto para ser vendido pelo mundo" $(2008: 1,2)$.

\section{Global versus local e adeptos}

A articulação entre o "global" e o "local" elucida todo o processo de transformação dos clubes locais e nacionais para transnacionais. Assim, o termo glocalization ajuda a explicar o modo como a simbiose do local e do global difere de acordo com circunstâncias culturais específicas (Giulianotti e Robertson, 2009). Num certo sentido, pode-se afirmar que todos os clubes transnacionais continuam a manter ligações à comunidade local, quer através dos nomes das equipas e dos estádios, quer através da sua base local de apoio. Ao manterem jogadores emblemáticos que personificam a identidade das equipas e dos adeptos, os clubes procuram não perder a sua raiz identitária. A este propósito vale a pena realçar as palavras de Giulianotti e Robertson: "nos mercados de trabalho do futebol, os clubes transnacionais ainda praticam glocalização cultural: concedem estatuto a figuras simbólicas nacionais ou locais e recrutam jogadores estrangeiros provenientes de nações culturais similares, ao mesmo tempo que procuram construir um reconhecimento global" (2004: 553).

Não se poderá afirmar que as reações dos adeptos face à implementação das políticas comer- 
ciais sejam unânimes. De facto, elas têm divergido consoante os casos e os contextos. Segundo Dubal (2010: 126), a maioria dos seguidores do Chelsea aceitou com satisfação a transformação do seu clube numa corporação transnacional, já que passaram a poder competir com os melhores clubes ingleses e europeus. No caso do Manchester United o cenário foi bem diferente, já que grande parte dos adeptos se posicionou veementemente contra este processo, levando, inclusivamente, uma fação de aficionados a formar outro clube ${ }^{8}$.

De acordo com a tese defendida por Sam Dubal (2010: 125), a mercantilização do futebol não constitui uma novidade: "o que é único nesta atual era de comercialização é o seu impacto dramático nos seguidores e na cultura de adepto". O reforço das políticas comerciais e financeiras no futebol alterou significativamente o quadro de relações que se estabelecem entre os aficionados e os clubes, originando a substituição dos adeptos por consumidores. Esta realidade constitui, sem dúvida, uma das características mais marcantes do futebol contemporâneo. A busca pela maximização do lucro e o afastamento dos adeptos tradicionais terá "roubado" o futebol dos adeptos (Bazel, 2011; Samuels, 2008). Nesta linha de pensamento, tem sido destacado o processo de gentrificação que tem percorrido os estádios, que diz respeito à substituição dos adeptos provenientes das classes trabalhadoras por consumidores dos estratos mais elevados da sociedade. Tal como realça Dubal (2010: 135), "o Manchester United já não é um lugar onde os adeptos das classes trabalhadoras podem desfrutar futebol a preços razoáveis, sendo agora um local onde os adeptos de classe média consomem futebol".

Pelo facto de se tratar de um exemplo paradigmático, o caso do Manchester United tem sido, na realidade, destacado por vários autores. Para além de ser, muito provavelmente, o clube com mais seguidores na Grã-Bretanha, o Manchester United, entre o fim da década de 1980 e princípios da década de 1990, obteve um brutal aumento de receitas provenientes da exponencial subida do preço dos bilhetes, da publicidade e das transmissões televisivas (King, 1998: 134). De acordo com a leitura de King (1998), o processo de gentrificação acima referido faz parte de um projeto mais vasto de transformação do futebol, para o qual contribuíram diversos fatores.

Nesse sentido, a criação do "cliente", além de representar um importante momento simbólico, é parte indissociável da transformação dos clubes em instituições orientadas para a obtenção do lucro. Anthony King (1998: 140) sublinha que, do mesmo modo que o princípio de mercado exclui os mais empobrecidos, os clubes de futebol também se acharam no direito de recusar a entrada a determinados adeptos. Assim, através do conceito de cliente, as novas gerações de diretores dos clubes procuraram reduzir as relações com os adeptos a uma mera transação económica:

\section{A transformação da relevância do futebol} (de utilidade pública para um negócio gerador de lucro) não só é significativa para a renegociação das relações sociais entre clubes e adeptos, como é determinante para o estabelecimento de princípios de mercado livre como culturalmente hegemónicos no quadro de uma sociedade pós-fordista (King, 1998: 145).

Tal como se tem procurado demonstrar, grande parte dos clubes de futebol, movidos pela procura do lucro, foram-se transformando em estruturas capitalistas corporativas. Os adeptos, por sua vez, guiados por sentimentos de paixão pelas suas equipas, viram-se relegados para uma posição desconfortável, já que as transformações no futebol, acima descritas, não deixaram de ter um impacto significativo no modo como estes "vivem" os seus clubes. Mas, enquanto a maior parte dos clubes se transfiguraram, houve outros que, juntamente com os seus adeptos, conseguiram manter-se com uma identidade própria que pouco tem que ver com o panorama neoliberal. Foi o caso do Athletic de Bilbao.

\section{Os processos de governação do Athletic de Bilbao}

Tendo em consideração todas as mudanças que têm ocorrido na regulação e governação do futebol, poder-se-ia esperar, da parte dos adeptos, indícios de enfraquecimento dos laços identitários que os ligam aos clubes, como sinal de uma crescente descaracterização do próprio futebol. Assim, o localismo, o regionalismo e o nacionalismo dariam lugar a um cosmopolitismo, enfraquecendo as culturas locais. No entanto, partindo do caso do Athletic de Bilbao é possível mostrar que as identidades locais e regionais se têm vindo a reforçar. Desde 1919 que o clube adotou uma política de governação que o torna um caso singular, especialmente no quadro global atual. A filosofia adotada pelo clube consiste em contratar apenas jogadores de origem basca que tenham sido formados no Athletic de Bilbao ou noutros clubes da região. Nas últimas décadas, a política de contratações alargou-se a jogadores que, não sendo oriundos do País Basco, tenham sido formados no clube. Esta filosofia constitui, nas palavras dos seus dirigentes, um motivo de orgulho: "convertendo-se numa componente de união que se sobrepõe a qualquer outro aspeto da nossa vida diária, marcando também a diferença em relação a qualquer outra filosofia ou forma de entender o futebol em todo o mundo" (http://www. athletic-club.net/). 
A evolução histórica do clube

Para um melhor entendimento das raízes desta política que demarca o Athletic de Bilbao de qualquer outro clube no mundo, convém olhar um pouco para o seu percurso histórico. Fundado em 1898 num contexto de crescente industrialização da cidade, o Athletic tornou-se um dos principais símbolos da identidade basca. Até 1936 o clube conquistou um grande número de troféus, tornando-se a equipa de Espanha com mais títulos. O seu estilo de jogo aguerrido e agressivo ganhou reconhecimento internacional e serviu, inclusivamente, de modelo para a própria seleção espanhola nos Jogos Olímpicos de 1920 (www.athletic-club.net). Um aspeto interessante que também merece ser salientado diz respeito ao funcionamento democrático do clube. Ao contrário da maioria dos clubes da altura, as grandes decisões eram tomadas pelos sócios, nomeadamente a eleição do presidente e restantes diretores (Duke e Crolley, 1996: 30).

Os três anos da Guerra Civil e o consequente período da ditadura franquista enfraqueceram a performance desportiva do clube. Ainda assim, foram determinantes para a consolidação e fortalecimento da sua identidade. Durante este período, as relações entre futebol e política foram intensas. O Athletic de Bilbao, tal como o F. C. Barcelona na Catalunha, representava a aspiração separatista e a rejeição da imposição da ideia de identidade nacional espanhola. Em 1937, os Bascos formaram uma equipa, Euskadi Republic, que partiu para uma digressão na Europa de Leste e na América do Sul com vista a angariar fundos e apoio para a causa independentista (MacClancy, 1996:191). No entanto, pouco tempo depois, a FIFA decidiu banir a equipa.

O forte envolvimento do Athletic com a equipa Euskadi, bem como o fortalecimento do apoio ao nacionalismo basco, estiveram na base da perda de prestígio de que o clube gozava até então no território espanhol (Duke e Crolley, 1996: 31). Com o fim da Guerra Civil e a consequente instauração do regime fascista liderado pelo general Franco, o futebol continuou a desempenhar um papel importante nas diferentes aspirações políticas: "Na Espanha de Franco, especialmente durante os primeiros anos, o futebol, tal como outras instituições públicas, caracterizava-se por um alto grau de intervenção das autoridades na sua administração, organização, propriedade e controle, sendo que as estruturas do desporto refletiam o regime político do país" (Duke e Crolley, 1996: 32).

Numa tentativa de homogeneização política e cultural, o regime franquista forçou o Athletic a uma mudança no nome, passando a designar-se, entre 1941 e 1975, Atlético de Bilbao, numa tentativa de aproximação do castelhano (www.athletic-club.net). Desenvolvendo a ideia de Duke e Crolley (1996),
Alejandro Soto (2014) mostrou, precisamente, a forma como o franquismo procurou utilizar o futebol como ferramenta de doutrinação das massas, recorrendo a todos os meios possíveis para associar os feitos das equipas e da seleção espanhola ao regime e, simultaneamente, acusando as potências estrangeiras de conspiração e responsabilizando-as pelas derrotas (Soto, 2014: 39).

Apesar da violência que caracterizou o fascismo espanhol e que se fez sentir nas diversas esferas da vida social, grande parte dos seus propósitos, especialmente no contexto do futebol, não foram alcançados, já que o Athletic continuou a ser uma arena privilegiada de celebração da identidade basca. Ou seja, longe de constituir um elemento de agregação e de união, o futebol na Espanha ditatorial espoletou, em algumas regiões, formas de contestação social, especialmente reivindicações separatistas $^{9}$. O envolvimento político do Athletic de Bilbao fez-se notar fortemente no período de transição democrática, nomeadamente na defesa da autonomia basca, no incitamento à aprendizagem do euskera, nas campanhas que exigiam a amnistia para os presos políticos, bem como na criação da seleção nacional basca (Soto, 2014; Shaw, 1987).

Em Goles y Banderas: Fútbol e Identidades Nacionales en España, Alejandro Soto (2014) explora, com algum detalhe, o papel desempenhado pelo Athletic de Bilbao e pela Real Sociedad enquanto fontes de identificação coletiva basca. Para uma perceção mais clara acerca da forma como o futebol, no País Basco, ocupou (e continua a ocupar) um espaço político altamente significativo, importa destacar dois episódios que ocorreram a meio da década de 1970: o primeiro ainda sob a ditadura militar e o segundo já durante o chamado período de "transição". Uma das ações políticas contestatárias levadas a cabo pelos jogadores do clube (e que alcançou um impacto bastante significativo no território basco) ocorreu dois meses antes da morte de Franco. Em outubro de 1975, após a execução de cinco membros da ETA e da FRAP, a equipa do Athletic entrou em campo com braçadeiras negras como forma de homenagear os revolucionários bascos. Apesar de o capitão da equipa ter afirmado, na altura, que o gesto não significava mais do que um ato comemorativo pelo falecimento de um antigo jogador e dirigente do clube, era por demais evidente que o uso das braçadeiras representava, sim, um protesto contra a brutalidade do regime militar franquista (Soto, 2014: 68).

Um ano após a morte de Franco, em dezembro de 1976, num jogo que opôs os dois maiores clubes bascos (Athletic de Bilbao e a Real Sociedad), os capitães de ambas as formações, após consultarem os restantes colegas de equipa, acordaram entrar em campo ostentando a bandeira do País Basco, perante o espanto e euforia dos adeptos (Soto, 2014: 
203). Refira-se que, apesar de esta manifestação já ter ocorrido no período de transição democrática, a exibição da ikurriña estava ainda proibida por lei, pelo que este gesto teve um enorme significado político.

Tal como realça Soto (2014), os episódios acima descritos vieram demonstrar, claramente, a ideia de que o "franquismo tinha perdido a batalha para impor a sua ideia de nação no País Basco" (Soto, 2014: 68). Com efeito, após o período que se seguiu à queda da ditadura militar, a sociedade basca desenvolveu uma enorme animosidade em relação à simbologia nacional espanhola e os símbolos bascos, muito devido às acções dos militantes do Herri Batasuna, rapidamente se tornaram hegemónicos (Soto, 2014: 211). Simultaneamente, as manifestações políticas que proclamavam a independência do País Basco foram ocorrendo nos estádios das principais equipas da região, com especial incidência para o recinto do Athletic de Bilbao e da Real Sociedad e, em menor dimensão, do Club Atlético Osasuna e do Deportivo Alavés.

$\mathrm{Na}$ verdade, os símbolos bascos, tal como a bandeira, continuam a marcar presença no estádio onde o Athletic joga, demonstrando que as ligações emocionais que ligam o clube à região continuam bem presentes no imaginário dos adeptos. Por outro lado, apesar do significado político e cultural das comemorações das recentes conquistas da seleção espanhola ocorridas em Bilbao, importa relativizá-las. Ou seja, ainda que a celebração da "identidade proibida" (espanhola) indicie a emergência de uma nova narrativa que conteste a hegemonia absoluta da identidade basca (Soto, 2014: 232), o retumbante apupo dos adeptos do Barcelona e do Athletic de Bilbao ao hino nacional, na final da Copa del Rey de 2015, indica a existência de um elevado grau de aversão relativamente aos símbolos estatais.

\section{Governação e identidade}

A política de governação que tem sido seguida pelo clube tem sido considerada por alguns como anacrónica e antiquada. A este propósito vale a pena destacar as palavras de Jonathan Shulman, quando sublinha: "no mercado contemporâneo do futebol europeu, a estrita contratação de talentos locais é praticamente suicida" (Shulman, 2004: 58). No entanto, é possível fazer uma leitura um pouco diferente. Numa época marcada pela crescente globalização, comercialização e mercantilização, em que a esmagadora maioria dos jogadores não constrói qualquer tipo de laço identitário que os una aos clubes que representam, este caso pode ser encarado como uma reação face à proclamada uniformização económica e cultural. Assim, o Athletic de Bilbao, perseverando os valores e sentimentos locais, parece constituir um símbolo da resistência contra o futebol globalizado (Castillo, 2007).
Contrariando a ideia de que a globalização iria resultar numa homogeneidade cultural, este caso demonstra que as culturas locais não assimilam passivamente as tendências políticas, económicas e culturais hegemónicas. Pelo contrário, elas manipulam qualquer produto cultural e redefinem-no de acordo com os seus valores. Tendo como exemplo o Athletic de Bilbao, as palavras de Dubal (2010: 124) ganham sentido quando afirma que "as reações dos adeptos face à implementação da governação de mercado tornam claro que a «neoliberalização», tal como a globalização, não transforma o mundo numa só sociedade neoliberal e nem os «fluxos» neoliberais atravessam as fronteiras livremente". Deste modo, os princípios de governação neoliberal são negociados de forma complexa mediante determinado contexto político, económico e cultural. Por outras palavras, o caso do Athletic sugere que, para uma leitura mais completa da realidade, há que ter em consideração a interdependência que se estabelece entre os processos locais e globais.

Uma questão importante que a filosofia seguida pelo clube levanta diz respeito ao êxito desportivo. Sendo o futebol uma prática cultural altamente competitiva, a conquista de troféus é, evidentemente, algo essencial para qualquer adepto. Neste sentido, tem sido argumentado que a política de contratação de jogadores exclusivamente bascos é incompatível, no panorama do futebol atual, com o sucesso desportivo (Shulman, 2004) ${ }^{10}$. No entanto, esta visão, ao centrar-se unicamente na obtenção de troféus, negligencia outros aspetos igualmente vitais para os seguidores de um clube.

Dados interessantes revelam que $76 \%$ dos adeptos do Athletic apoiam incondicionalmente a filosofia do clube, mesmo que isso implique a despromoção para a segunda divisão espanhola (McClancy, 1996: 195). É nesse sentido que as palavras de Dougie Brimson ganham relevância quando afirma que "ser um adepto de futebol não tem propriamente que ver com assistir a um grande jogo. Trata-se, sim, de investir tempo e de pertencer a algo, à entidade que é o clube de futebol" (Brimson, 2000: 35). Contudo, quando os grandes êxitos são alcançados, os adeptos sentem-se no direito de reclamar a "sua parte" (Almeida, 2006: 25).

O debate sobre a política de governação do Athletic tem sido ocasionalmente travado, principalmente quando o clube é forçado a despender elevadas quantias de dinheiro para contratar jogadores bascos formados em outros clubes da região. No entanto, os fortes laços identitários que ligam o clube à cidade e ao País Basco têm permitido ao Athletic não só continuar com esta filosofia de governação, como também reforçar a posição dos seus sócios, que, desafiando a tendência recente, rejeitaram veementemente a conversão do clube numa sociedade anónima desportiva (Soto, 2014: 
227). Tal como salienta Alejandro Soto (2014), os efeitos da globalização e da mercantilização tiveram um efeito devastador, não só para diversos clubes europeus, como inclusivamente para outros clubes bascos, particularmente para o Deportivo Alavés.

Com efeito, o Deportivo Alavés transformou-se num caso paradigmático no que concerne ao difícil equilíbrio entre capital externo, identidade local e futebol pós-moderno. Comprado em 2003 por um milionário norte-americano, o clube esteve em vias de extinção após o novo proprietário o ter endividado brutalmente. Além disso, o dono do Alavés cortou relações com os autarcas da cidade de Vitória e rompeu os elos de ligação com os próprios adeptos. Após uma disputa jurídica, que se prolongou entre 2007 e 2012, interposta pelos novos dirigentes contra Dmitri Piterman, o antigo proprietário foi condenado a pagar uma indeminização ao clube no valor de 6,8 milhões de euros (Soto, 2014: 228).

A noção de "comunidade imaginada" desenvolvida por Benedict Anderson (2005) pode elucidar a forma como os adeptos de futebol projetam, nos clubes que apoiam, determinadas imagens de coletividade, de partilha de uma história comum. Explorando os mecanismos que estiveram na génese das raízes culturais do nacionalismo, o autor defende a ideia de que as comunidades não se distinguem pelo seu carácter falso ou genuíno, mas sim pelo modo como são imaginadas. Assim, qualquer nação não é mais do que uma comunidade política imaginada, na medida em que, como afirma Anderson (2005: 25), "os seus membros nunca conhecerão, nunca encontrarão e nem ouvirão falar da maioria dos outros membros dessa mesma nação, mas, ainda assim, na mente de cada um existe a imagem da sua comunhão".

O apelo à "comunidade imaginada" é um processo que se encontra fortemente presente na cultura do futebol. De facto, no imaginário dos aficionados, um jogo de futebol representa a disputa entre duas comunidades distintas, cada uma com as suas particularidades. O que é interessante é que a construção simbólica que se produz e reproduz ao nível discursivo acaba por ganhar um sentido "real", através da construção de vínculos (que, no caso do Athletic, são, igualmente, políticos e ideológicos) que unem os adeptos de um determinado clube.

Focando-se na sua comunidade local e conseguindo manter-se num elevado patamar competitivo, o clube tem sido capaz de se conservar economicamente sustentável. Para além disso, os seus associados continuam a ter uma voz ativa nas grandes decisões, o que já não acontece em muitos dos grandes clubes europeus. Tal como salienta Castillo (2007: 28), o Athletic tem persistido no desafio ao espírito da absoluta comercialização pós-moderna, ao ter-se mantido até há poucos anos um dos poucos clubes sem qualquer publicidade inscrita no equipamento oficial. As particularidades que o caracterizam trouxeram-Ihe não só a devida notoriedade mundial como também o respeito de muitos adeptos espanhóis de outros clubes e regiões (Unzueta, 1999). Sendo o futebol um desporto que enfatiza a noção de território e que assenta, em larga medida, na rivalidade e na oposição ao "outro", esta admiração não deixa de ser notável, sobretudo num país marcado por fortes sentimentos regionalistas e independentistas.

\section{Considerações finais}

Tal como se pretendeu demonstrar neste artigo, o rumo neoliberal que tem guiado as sociedades contemporâneas teve um impacto muito significativo na forma como se concebe, hoje, o futebol aos mais variados níveis. Partindo da ideia de que o desporto em geral e o futebol em particular constituem um campo privilegiado de acesso ao estudo da realidade, procurou-se com este trabalho contribuir para um melhor entendimento na forma como os atores sociais, especialmente os clubes e adeptos, negoceiam a entrada das políticas de mercado livre na arena desportiva.

Uma das ilações que se pode tirar refere-se à possibilidade de se construírem novas formas que, de algum modo, sejam capazes de desafiar as políticas económicas dominantes. Se tomarmos como exemplo o caso do Athletic de Bilbao, concluímos que, ao contrário daquilo que já tem sido defendido, o mercantilismo não deve ser entendido como uma inevitabilidade histórica. No atual quadro global, esta perspetiva poderá parecer um pouco romântica. No entanto, uma visão puramente economicista da realidade também se apresenta algo redutora. Parte dos adeptos de futebol, através de um processo simbólico de resgate de fronteiras, parece querer ir contra a direção global das sociedades contemporâneas. Apelando à união da "comunidade imaginada" localizada, os seguidores e dirigentes do Athletic procuram, por um lado, a recuperação nostálgica dos "velhos valores" do futebol, na forma como um clube pode ser representativo de uma determinada comunidade. Por outro lado, tendo em consideração o contexto político, social e cultural no qual o clube se insere, facilmente se percebe que a sua filosofia de governação se encontra igualmente direcionada para a afirmação e celebração da identidade basca. Não obstante, dada a longevidade da política adotada pelo Athletic, não se poderá deixar de destacar o seu papel desafiador e contra-hegemónico na resistência à implementação de políticas puramente comerciais de cariz mercantil que, ainda que possam trazer êxito desportivo, desvirtuam e descaracterizam as especificidades que estiveram na base do nascimento do futebol. 


\section{Notas}

${ }^{1}$ O hooliganismo refere-se a uma subcultura de adeptos, originária na Grã-Bretanha em finais de década de 1960, e que se caracteriza, essencialmente, pela procura de confrontação física ou simbólica com outros grupos rivais e/ou com as forças policiais.

2 De entre estas medidas, destacaram-se o aumento das penas por envolvimento em atos de violência, a eliminação de lugares em pé nos estádios, o aumento do preço dos bilhetes, o reforço policial dentro e fora dos estádios e a "segregação" dos adeptos "visitantes" em espaços delimitados e vigiados.

3 Por exemplo, a abordagem marxista de Ian Taylor sobre a violência no futebol, no início da década de 1970, defendia a ideia de que o hooliganismo era o reflexo da profunda mudança do próprio futebol, em particular das alterações registadas nos clubes locais enquanto instituições ligadas às classes trabalhadoras (cf. Dunning et al., 2002).

${ }^{4}$ A organização do Campeonato Mundial de Seleções de 2014, que decorreu no Brasil, proporcionou à FIFA a obtenção de um valor recorde na história dos Mundiais de Futebol, situado na ordem dos 2,6 mil milhões de dólares (http://www.opovo.com.br/app/opovo/esportes/2015/03/21/noticiaesportesjornal,3410631/copade-2014-da-lucro-recorde-para-a-fifa.shtml).

${ }^{5}$ Apesar da complexidade do sistema de apuramento para a Champions League, não deixa de ser significativo o facto de 16 das 32 equipas que participaram na "fase de grupos", na edição de 2014/2015, serem provenientes dos cinco campeonatos onde o futebol gera mais dinheiro, enquanto as restantes 16 equipas se distribuem por 13 países. Para além dos 8,6 milhões de euros atribuídos pela participação na prova, os clubes, nesta fase da competição, são premiados com 1 milhão de euros por cada vitória e 500 mil por empate. De salientar, ainda, que, das 16 equipas que se qualificaram para a fase seguinte da prova, 12 são provenientes de Inglaterra, Alemanha, Espanha, Itália e França.

${ }^{6}$ Informações oficiais fornecidas pela UEFA vão ao encontro das ideias apresentadas referentes às receitas milionárias geradas pela competição. $\mathrm{Na}$ edição da prova de 2013/2014, por exemplo, a UEFA distribuiu, pelos 32 clubes participantes, 904 milhões de euros. 0 Real Madrid, vencedor da prova, recebeu 57,4 milhões de euros, cerca de metade dos quais proveniente de prémios da UEFA e o restante oriundo do mercado de transmissões televisivas. Os outros clubes com maiores receitas, acima dos 40 milhões de euros, foram o Paris S.-G. (França), o Manchester United F. C. e Chelsea F. C. (Inglaterra), Juventus F. C. (Itália), F. C. Bayern Munique (Alemanha), e F. C. Barcelona (Espanha) (http://pt.uefa. com/uefachampionsleague/news/newsid $=2117835$.html)

7 O Chelsea F. C. foi adquirido, em 2003, por Roman Abramovich por cerca de 210 milhões de euros (http:// www.dn.pt/inicio/interior.aspx?content_id=653084) enquanto o Manchester United F. C. foi comprado pelo norte-americano Malcom Glazer, em 2005, por cerca de 790 milhões de libras (Dubal, 2010: 134). A estes clubes seguiram-se outros casos, tais como o do Manchester City, adquirido, em 2007, pelo antigo primeiro-ministro tailandês Thaksin Shinawatra, do Paris Saint-Germain, comprado por um grupo de investidores do Catar em 2011 e, em 2014, do Valência, adquirido pelo singapurense Peter Lim.

8 Fundado em 2005, o F. C. United of Manchester é uma equipa semiprofissional que milita na Northern Premier League. O clube é gerido de forma democrática pelos seus quatro mil membros e encontra-se altamente comprometido com a comunidade local, sendo que grande parte dos fundos adquiridos é direcionada para instituições sociais (http://www.fc-utd.co.uk/waw.php).

9 Da mesma forma que o Athletic de Bilbao tem servido de arena de celebração da identidade basca (por oposição à espanhola), também o Barcelona, desde a governação de Primo de Riviera, tem sido aglutinador do "catalanismo". De uma forma geral, a narrativa dominante na Catalunha apresenta o Barcelona como um representante legítimo da nação catalã democrática por oposição ao Real Madrid, conotado com a essência do militarismo, do autoritarismo, da repressão e do centralismo político (Soto, 2014).

10 Os resultados recentemente obtidos pelo clube desmentem esta tese. Além da conquista da Supercopa de Espanha em agosto de 2015, o Athletic de Bilbao disputou a edição de 2014/2015 da Champions League e foi finalista da Copa del Rey. Acrescente-se, ainda, uma presença na final da Europe League, na época de 2011/2012.

\section{Referências bibliográficas}

ALABARCES, P. (2002), "Aguante and Repression: football, politics and Violence in Argentina", in E. Dunning et al. (eds.), Fighting Fans as a World Phenomenon, Dublin, University College Press, 23-36.

ALMEIDA, P. (2006), Violência e Euro 2004. A centralidade do futebol na cultura popular, Lisboa, Colibri.

ANDERSON, B. (2005), Comunidades Imaginadas: Reflexões sobre a Origem e a Expansão do Nacionalismo, Lisboa, Edições 70.

ARMSTRONG, G. (1998), Football Hooligans, Knowing the Score, Oxford, Berg.

ASTRINAKIS, A. (2002), "Subcultures of hard-core fans in West Attica: an analysis of some central research findings", in E. Dunning et al. (eds.), Fighting Fans as a World Phenomenon, Dublin, University College Press, 88-105.

BANKS, S. (2002), Going Down. Football in Crisis: How the game went from boom to bust, Edimburgo, Mainstream Publishing.

BAZEL, M. (2011), Theatre of Silence: the lost soul of football, Cambridge, Pegasus.

BRIMSON, D. (2000), Barmy Army: The Changing Face of Football Violence, Londres, Headline Book Publishing.

CASTILLO, J. C. (2007), "The concept of loyalty and the challenge of internationalisation in post-modern Spanish Football", International Journal of Iberian Studies, 20 (1), 23-40.

DUBAL, S. (2010), "The Neoliberalization of football: rethinking neoliberalism through the commercialization of the beautiful game", International Review for the Sociology of Sport, 45 (2), 123-146. 
DUKE, V. e L. Crolley (1996), Football, Nationality and the State, Edimburgo, Longman.

DUNNING, E. (1993), "The Social Roots of Football Hooliganism: A Reply to the Critics of the «Leicester School»", in N. Bonney et al. (eds.), Football, Violence and Social Identity, Londres, Routledge, 128-157.

DUNNING, E. et al. (2002), "Towards a Sociological Understanding of Football Hooliganism as a World Phenomenon", in E. Dunning et al. (eds.), Fighting Fans as a World Phenomenon, Dublin, University College Press, 1-22.

GIULIANOTTI, R. e R. Robertson (2004), "The Globalization of Football: a study in the glocalization of the «serious life»", The British Journal of Sociology, 55, 545-568.

GIULIANOTTI, R. e R. Robertson (2009), Globalization and Football, Londres, Sage.

HARVEY, D. (2005), A Brief History of Neoliberalism, Oxford, University Press.

KING, A. (1998), The End of the Terraces: the Transformation of English Football in the 1990's, Londres, Leicester University Press.

LAGO, A. e R. Biasi (1994), "Italian Football Fans: Culture and Organization", in Booney et al. (eds.), Football, Violence and Social Identity, Londres, Routledge, 73-89.

MACCLANCY, J. (ed.) (1996), "Nationalism at play: the Basque of Vizcaya and Athletic Bilbao", in J.McClancy, Sport, Identity and Ethnicity, Oxford, Berg, 167-199.

MARIVOET, S. (2009), "Subculturas de adeptos de futebol e hostilidades violentas - o caso português no contexto europeu", Configurações, 5 (6), 279-289.

MARSH, P. (1978), Agro: the Illusion of Violence, Londres, Dent.

PIMENTA, C. (2000), "Violência entre Torcidas Organizadas de Futebol", São Paulo em Perspectiva, 14 (2), 122-128.

POLANYI, K. (2007), La Gran Transformación: critica del liberalismo económico, Madrid, Quipu Editorial.

SAMUELS, J. (2008), The Beautiful Game is over: the Globalization of Football, Brighton, Book Guild Publishing.

SHAW, D. (1987), Fútbol y Franquismo, Madrid, Alianza.

SHULMAN, J. (2004), "The Last Genuine Local Team: Athletic Bilbao Surviving in the Spanish League", Dialogues@Ru,3,57-71.

SOTO, A. (2014), Goles y Banderas: Fútbol e Identidades Nacionales en España, Madrid, Marcial Pons.

SUGDEN, J. et al. (1998), "FIFA versus UEFA in the struggle for the control of world football", in A. Brown (ed.), Fanatics! Power, Identity and Fandom in Football, Londres, Routledge, 11-31.

SZYMANSKI, S. (2010), Football Economics and Policy, Hampshire, Palgrave Macmillam.

TAYLOR, M. (2007), Politics and the People's Game: Football and Political Culture in Twentieth Century Britain, 1-18, disponível em www.idrottsforum. org/ articles/taylor/taylor070117.html.

UNZUETA, P. (1999), "Fútbol y Nacionalismo Vasco", in S. Segurola (ed.), Fútbol y Pasiones Políticas, Madrid, Debate, 147-167. 